\title{
Canary grasses (Phalaris, Poaceae): Molecular phylogenetics, polyploidy and floret evolution
}

\author{
Stephanie M. Voshell, ${ }^{1}$ Riccardo M. Baldini, ${ }^{2}$ Rohit Kumar, ${ }^{1}$ Nicholas Tatalovich ${ }^{1}$ \& Khidir W. Hilu ${ }^{1}$ \\ 1 Department of Biology, Virginia Tech, Blacksburg, Virginia 24061, U.S.A. \\ 2 Dipartimento di Biologia Evoluzionistica, Università degli Studi, Via G. La Pira 4, 50121 Firenze, Italy \\ Author for correspondence: Stephanie M.Voshell, svoshell@vt.edu
}

\begin{abstract}
The 21 wild species of Phalaris L. (Poaceae) are distributed in temperate areas of both hemispheres and in the mountains of tropical Africa and South America. The genus contains annual and perennial diploids based on $x=6$ and 7 and polyploids based on $x=7$, with the $x=6$ cytotypes displaying less species diversification. Phalaris presents a potentially valuable case study for speciation in conjunction with chromosomal evolution and biogeography in Poaceae due to its global distribution, notable variation in morphological traits, and the key role of polyploidy in its evolution. We reconstructed the first phylogenetic tree for the genus using nuclear ITS and plastid trnT-F sequences to assess species relationships and map trends in floret differentiation and patterns of polyploid evolution. The study demonstrated a single origin of the $x=6$ chromosome number and revealed the sister relationship of this lineage to the monophyletic $x=7$ lineage. The clades recovered in the analyses display geographic affiliations and demonstrate diploid-polyploid associations. A trend in sterile lemma reduction is evident, with members of the early diverging $x=6$ lineage displaying relatively large and lanceolate sterile lemmas, followed by gradual reduction in size, culminating in almost obsolete sterile lemmas in one of the terminal $x=7$ clades.
\end{abstract}

Keywords biogeography; chromosome evolution; ITS; phylogeny; trnT-F

Supplementary Material The alignment is available in the Supplementary Data section of the online version of this article (http://www.ingentaconnect.com/content/iapt/tax).

\section{口INTRODUCTION}

Phalaris L. (Poaceae) comprises 21 wild species (Baldini, 1995) distributed in temperate areas of both Northern and Southern Hemispheres and the mountains of tropical Africa and South America (Fig. 1). Phalaris is placed either in the traditional Aveneae tribe (Clayton \& Renvoize, 1986) or in a primarily Aveneae lineage in a recent molecular phylogenetic study of Pooideae (clade 1, Schneider \& al., 2009). We will follow the traditional Aveneae classification in this paper. The genus contains annual and perennial diploids based on $x=6$ and $x=7$ chromosome numbers and polyploid species based on $x=7$ (Parthasarathy, 1938; Ambastha, 1956; McWilliam \& Neal-Smith, 1962; Stebbins, 1971; Kadir, 1974; Hunziker \& Stebbins, 1987). Phalaris includes important forage crop species such as $P$. canariensis L., and some weedy and invasive species such as $P$. arundinacea $\mathrm{L}$.

Phalaris is characterized by laterally compressed ovate spikelets with a single fertile floret and two proximal sterile lemmas. The florets are subtended by two lower persistent glumes that are subequal, large, awnless, usually flattened, and dorsally keeled. Phalaris paradoxa L. and P. coerulescens Desf. deviate in having spikelets assembled into deciduous clusters of one fertile and up to 6-7 sterile spikelets. The sterile lemmas of Phalaris are subulate and shorter than the fertile one. The fertile lemmas are coriaceous, acute, awnless, and the margins are not overlapping. The palea is coriaceous, bi-nerved, and awnless. Anderson (1961) recognized four floret types in Phalaris and
Baldini (1995) further divided the fourth type into three, resulting in a total of six floret types. Baldini (1995) underscored the potential usefulness of floret types in the systematics of the genus. The six floret types are illustrated in Fig. 2.

Phalaris along with Anthoxanthum L. and Hierochloe R. Br. possess a distinctive spikelet structure and are members of the traditional subtribe Phalaridinae Rchb. within Aveneae (Clayton \& Renvoize, 1986; Soreng \& al., 2003). Soreng \& Davis (2000) recovered Phalaris, Anthoxanthum, and Hierochloe in one clade based on phylogenetic analysis of chloroplast restriction data and morphological characters. Phalaris appeared in an individual clade sister to these two genera in phylogenetic studies based on DNA sequences (Döring \& al., 2007; Quintanar \& al., 2007). Although Quintanar \& al. (2007) consider Phalaris as an isolated genus of uncertain phylogenetic relationship in Aveneae, their trnT-F tree resolved Anthoxanthum + Hierochloe and Briza L.+Airopsis Desv. in subclades diverging directly after Phalaris, implying close phylogenetic relationships. The taxonomic and nomenclatural history of Phalaris and its infrageneric delimitation have been discussed in Paunero (1948), Anderson (1961), Clayton \& Renvoize (1986), Baldini \& Jarvis (1991), and Baldini (1993, 1995). In a morphological study focused on Phalaris in Spain, Paunero (1948) recognized four species and two sections: sect. Baldingera (Gaertn.) Paunero comprising P. arundinacea, and sect. Euphalaris Paunero, encompassing the remaining three species. Anderson (1961) recognized 15 species and Baldini (1995) and Kodela \& al. (2009) listed 22 species for the genus (including 
the artificial hybrid species $P$. daviesii S.T. Blake); neither study proposed an infrageneric classification. Rauschert (1969) and Valdés \& Scholz (2006) raised P. arundinacea to a generic level, Phalaroides Wolf, based on morphological data. All the previously mentioned taxonomic studies were based on intuitive assessments using morphological features. A phylogenetic study for the genus based on structural and/or molecular information is lacking.

Phalaris grows in diverse habitats ranging from wild communities to disturbed areas, generally at low altitudes in open grounds, old fields, sandy soils, and waste beds (Baldini, 1995). Phalaris arundinacea, P. rotgesii (Husnot) Baldini, P. caesia Nees, $P$. peruviana $\mathrm{H}$. Scholz \& Gutte, and $P$. lindigii Baldini occupy lacustrine habitats. A number of species, such as
P. arundinacea, can grow in permanently aquatic habitats, and populations of $P$. aquatica $\mathrm{L}$. and $P$. coerulescens are subject to seasonal flooding.

Anderson (1961) and Baldini (1995) proposed the European-Mediterranean and Macaronesian regions as the primary areas of speciation and Southwestern U.S.A. as a secondary center of differentiation for Phalaris. The North European $P$. arundinacea is the most widespread species, extending across the circumboreal region (Fig. 1). Merigliano \& Lesica (1998) proposed a "native" status for this species in a small section of western North America and indicated that the North American populations are a mix of native strains and agronomic cultivars (see also Barkworth, 2007). Casler \& al. (2009) analyzed AFLP markers and chloroplast DNA sequence data

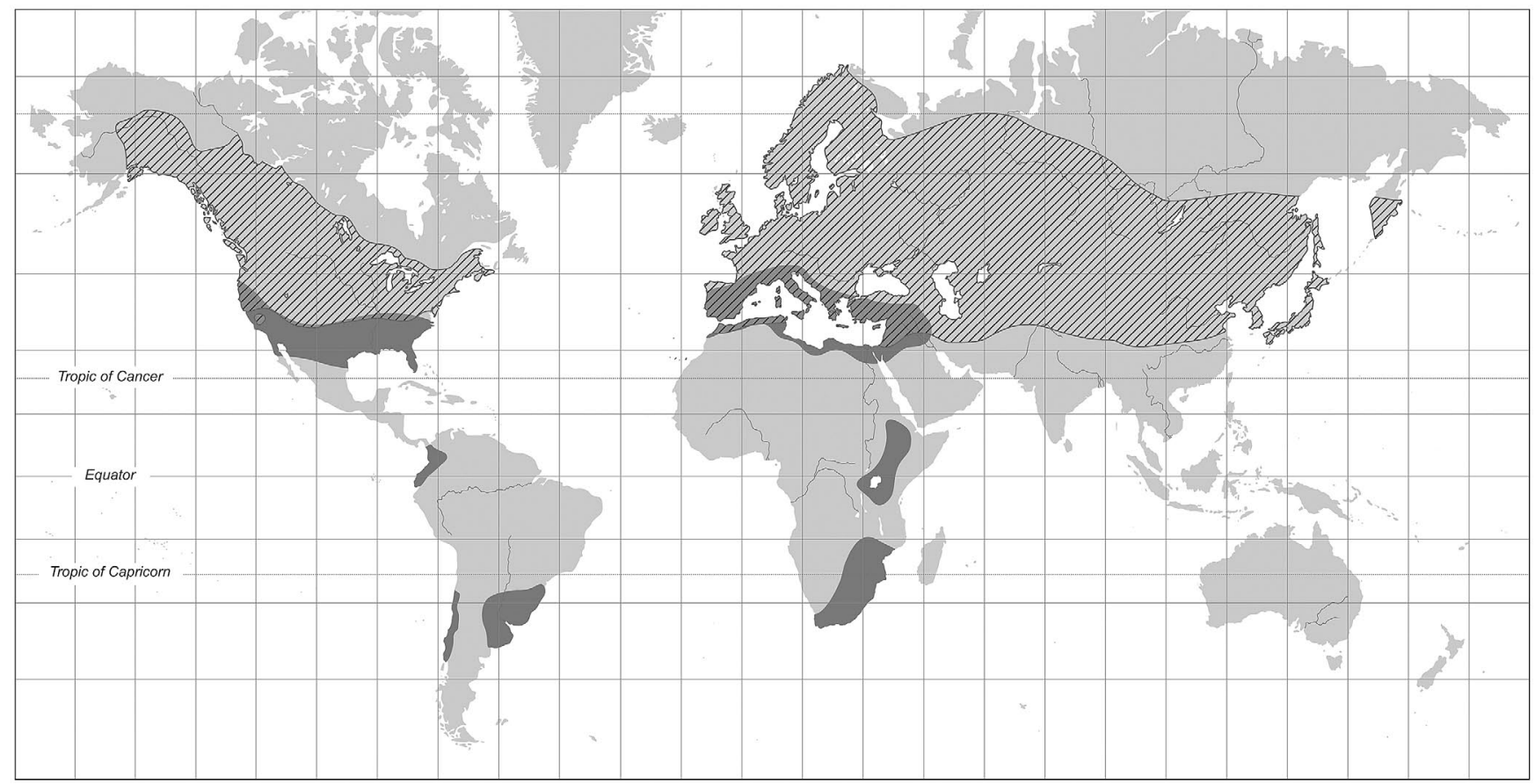

Fig. 1. Geographic distribution of canary grasses (Phalaris). Area in stripes denotes the distribution of $P$. arundinacea and solid areas represent other Phalaris species. Note the Mediterranean association, disjunct distribution in Africa and South America, and wide distribution in the Northern Hemisphere.

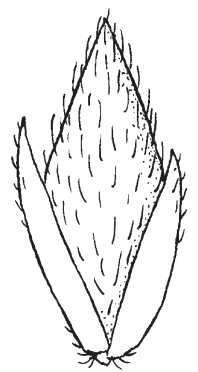

1

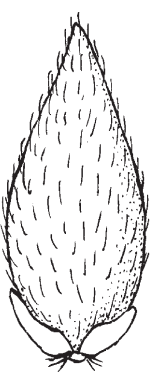

2

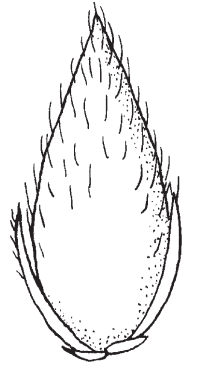

3

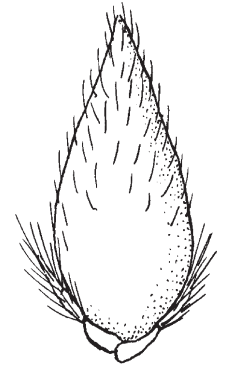

4

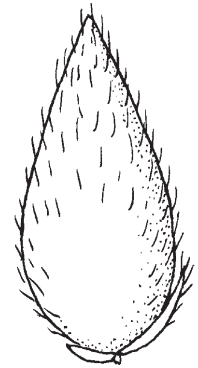

5

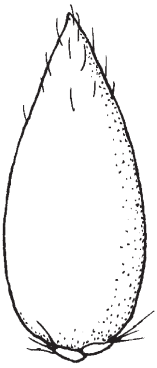

6

Fig. 2. A diagrammatic illustration of six floret types recognizable in species of Phalaris following Anderson (1961) and Baldini (1995). Note the central fertile floret and the two lateral sterile lemmas that display successive reduction in size. 
of P. arundinacea with Unweighted Pair Group Method Using Arithematic Averages (UPGMA) and revealed higher genetic diversity in Europe and a limited gene pool in western North America. They concluded that the presence of $P$. arundinacea in western North America is potentially the result of limited natural migration. The Neotropics and southern temperate South America represent additional areas of speciation for Phalaris. The Neotropics contain the two endemic perennials $P$. lindigii and P. peruviana, while southern temperate South America has the two annual endemics $P$. amethystina Trin. and $P$. platensis Henrard ex Wacht. Further, North and South America share the disjunct populations of $P$. angusta Nees ex Trin. whereas a vicariance biogeography has been proposed for P. lemmonii Vasey-P. platensis (Henrard, 1938).

The objectives of this study were to use DNA sequence information from the nuclear ribosomal internal transcribed spacer (ITS) and the plastid trnT-F region from Phalaris species to reconstruct a phylogenetic tree and use it for the assessment of species relationships and polyploid and floret evolution.

\section{MATERIALS AND METHODS}

Species sampling. - The ITS and trnT-F regions were sequenced from 39 and 30 accessions, respectively, representing 20 of the 22 species of Phalaris recognized by Baldini (1995; Appendix). Plant material for $P$. elongata Braun-Blanq., which is now considered as a variety of $P$. aquatica (Oram \& al., 2009), was unavailable, and the synthetic allopolyploid $P$. $d a-$ viesii was excluded since the focus of the study was on the wild species. The two genomic regions were chosen based on their documented utility in phylogenetics at this level and their differential mode of inheritance (bipaternal vs. maternal) that may potentially help discern patterns of polyploid evolution. For the ITS dataset, more than one accession per species was used whenever feasible; the number of accessions was increased when molecular variation was detected, such as with $P$. minor Retz., P. paradoxa, P. caroliniana Walt., and P. californica Hook. \& Arn. (see Appendix). For the trnT-F, the number of accessions was reduced to mostly one per species due to the low level of variation in nucleotide substitutions encountered in this genus. Accessions for a species with identical DNA sequences were represented by one accession in the dataset to speed up phylogenetic analyses. Sources and geographic origin of the material and chromosome counts are noted in the Appendix.

DNA isolation, amplification, and sequencing. - For fresh material, genomic DNA was isolated following Doyle \& Doyle (1990). In the case of herbarium samples (often 20 to 60 years old), the DNA isolation method was modified to optimize the procedure. In those cases, the ground leaf material was extracted two to three times in $\mathrm{CTAB}+$ Beta-mercaptoethanol and the supernatant solutions collected from each extraction were combined to increase the amount of DNA recovered. Additionally, the solution was allowed to remain at $-20^{\circ} \mathrm{C}$ overnight at the DNA precipitation step. The ITS region was amplified using the universal primers ITSA and ITSB (Downie \& Katz-Downie, 1996) and the Polymerase Chain Reaction
(PCR) method described in Woods \& al. (2005). The trnT-F region was amplified using universal primers and the protocol from Taberlet $\&$ al. (1991) with a $50^{\circ} \mathrm{C}$ annealing temperature. The region was either amplified in two segments using the primers $\operatorname{trn} \mathrm{A} / \operatorname{trnC}$ and $\operatorname{trnC} / \operatorname{trnF}$, or in three sections in cases of degraded genomic DNA using the primer combinations $\operatorname{trn} \mathrm{A} /$ $\operatorname{trn} B, \operatorname{trnC} / \operatorname{trn} D$, and $\operatorname{trnE} / \operatorname{trnF}$. Amplification products for both genomic regions were resolved on $0.8 \%$ TAE-agarose gels, excised, and cleaned using QIAquick PCR purification or QIAquick Gel Extraction kits (Qiagen, Valencia, California, U.S.A.) or the Promega Wizard SV Gel \& PCR Clean-Up System (Promega, Madison, Wisconsin, U.S.A.). Cycle sequencing was performed using the ABI PRISM Big Dye terminator Cycle Sequencing kit v.3.1 (Applied Biosystems, Foster City, California, U.S.A.), and the products were resolved using Applied Biosystems 3730 automated sequencer at the Core Sequencing Facility at Virginia Bioinformatics Institute, Virginia Tech, or at the DNA Analysis Facility of Duke University.

Outgroup selection. - Anthoxanthum monticola (Bigelow) Veldkamp and Hierochloe equiseta Zotov were selected as outgroup in the ITS phylogenetic analyses. In the case of the trnT-F analyses, sequences for $H$. australis (Schrad.) Roem. $\&$ Schult. were substituted for $H$. equiseta due to unavailability of genomic DNA and GenBank sequences for the latter species. Briza minor L. alone and in combination with the above outgroup taxa were also considered for rooting the tree, but the phylogenetic structure (resolution and support) was reduced in comparison with those based on Anthoxanthum and Hierochloe. Traditional and current systematic studies have demonstrated that the three genera are closely related (see Introduction).

Sequence alignment and phylogenetic analyses. The ITS and $\operatorname{trnT}-F$ sequences were manually aligned using Quickalign v.1.03 (Müller, 2004). Gaps were inserted at the cost of two or more substitutions and coded into the alignment matrix file using SeqState v.1.32 (Müller, 2005) and selecting the Simple Coding option (Simmons \& Ochoterena, 2000). Double peaks detected in the ITS phenograms were assigned IUPAC ambiguity codes. The two datasets were analyzed separately and in combination using maximum parsimony (MP) in PAUP* (Swofford, 2002) and Bayesian inference (BI) in Mr. Bayes v.3.0b4 (Huelsenbeck \& Ronquist, 2001; Ronquist $\&$ Huelsenbeck, 2003).

In the MP analysis, heuristic searches were performed with all characters equally weighted. Stepwise addition for 1000 replicates was implemented with TBR branch swapping, MULPARS on, and steepest descent off. A strict consensus tree was computed from all shortest trees. Maximum parsimony bootstrap (BS) values as a measure of clade support (Felsenstein, 1985) were obtained by conducting searches of 1000 iterations with 10 random sequence replicates. In the BI analysis, the Markov Chain Monte Carlo (MCMC) method (Larget \& Simon, 1999; Lewis, 2001) was implemented. Optimal models of sequence evolution and starting likelihood parameters were determined using Modeltest v.3.7 (Posada \& Crandall, 1998), and the GTR + G model was shown to be the best fit model for both ITS and trnT-F datasets. Four Markov chains were simultaneously run for 1,000,000 generations, starting with a random 
tree, and with trees and parameters being sampled every 1000 generations. The analyses reached stationarity where the average standard deviation of split frequencies between runs was $\leq 0.01$ prior to the end of the runs. The first 2500 'burn in' trees were discarded, and the rest were used to compute a $50 \%$ majority-rule consensus tree. The posterior probabilities (PP) were calculated and stored for each tree.

To determine the potential of combining the ITS and trnT-F sequence data for phylogenetic analyses, we used a partition homogeneity test (PHT; Farris \& al., 1995). The whole $t r n T-F$ dataset (30 accessions/20 species) and only the corresponding ITS sequences were used in the test to achieve completely overlapping datasets. The PHT was performed in PAUP* with 100 replicate partitions and 1000 trees per replicate. Significant heterogeneity was found between the two genomic regions $(P=0.01)$, implying significant incongruence between the two datasets. We also performed the PHT using only variable characters as recommended by Cunningham (1997) but the outcome remained the same. Although the results suggest that the two datasets are not compatible, we opted to analyze a combined dataset composed of completely overlapping sequences, i.e., ITS sequences for accessions that do not have corresponding trnT$F$ sequences were excluded. Our reasoning for the combined analyses was that the PHT tends to be overly sensitive to noise and differences in tempo of evolution of genomic regions and, as a result, might not accurately reflect congruencies (Dolphin \& al., 2000; Barker \& Lutzoni, 2002; Darlu \& Lecointre, 2002). Furthermore, our partitioned analyses demonstrated that differences between the topologies of the trees derived from the two regions do not represent hard incongruence (Seelanan \& al., 1997).

To evaluate trends in floret character evolution among species, we mapped on the phylogenetic trees the six Phalaris floret types (Fig. 2) recognized in Baldini (1995) based on sterile lemma structure: Type 1, two chaff-like; Type 2, two reduced coriaceous: Type 3, two equal or subequal; Type 4, two equal or subequal feathery; Type 5, one well-developed sterile lemma; and Type 6, two obsolete sterile lemmas. Chromosome numbers were also mapped on the tree to reflect shifts in basic chromosome number ( $x=6$ and $x=7)$ as well as ploidy levels.

\section{RESULTS}

ITS dataset. - The ITS region varied in length from 588 bp (P. rotgesii) to 602 bp (P. arundinacea). After insertions of 14 gaps of 1 to $3 \mathrm{bp}$ in length, the alignment was 732 characters long. Following the exclusion of portions at the ends of the alignment due to missing data, the number of characters used in the analysis was reduced to 618 including indels. There were 169 variable characters, out of these 142 were parsimony informative (PI). The MP analysis recovered 113,417 equally parsimonious trees of 231 steps, with consistency index (CI) and retention index (RI) values of 0.831 and 0.952 , respectively.

Tree topologies obtained from the MP and BI analyses are completely congruent and therefore will be discussed together.
The monophyly of Phalaris received maximum BS and PP support (Fig. 3). A split into two clades is evident at the base of the genus. One clade ( $99 \%$ BS, 1.00 PP) comprises $P$. truncata Guss. ex Bertol. sister to $P$. canariensis plus $P$. brachystachys Link (100\% BS, 1.00 PP). All members of this clade have a basic chromosome number of $x=6$ as a synapomorphy and possess floret type 1 (P. canariensis) and type 2 (P. truncata, $P$. brachystachys). The second clade (97\% BS, 1.00 PP) includes species having $x=7$. Species in this clade form three strongly supported lineages, which we will refer to informally as lineage 1, 2, and 3. Lineage 1 (95\% BS, $1.00 \mathrm{PP})$ represents species endemic to North and South America (P. californica, P. caroliniana, $P$. amethystina, $P$. platensis, $P$. lemmonii) and one species ( $P$. angusta) found in both North and South America. Phalaris angusta appears in a clade with P. lemmonii, $P$. amethystina, and P. platensis (89\% BS, $1.00 \mathrm{PP})$ sister to two clades representing $P$. californica and $P$. caroliniana. Members of this group share floret type 3 as a synapomorphy. Lineage 2 $(100 \%$ BS, 1.00 PP) includes a diploid (P. rotgesii), a tetraploid (P. arundinacea), and a hexaploid (P. caesia), as well as $P$. peruviana (chromosome number unknown) in a polytomy (Fig. 3). Members of this group possess floret type 4. Lineage $3(96 \%$ BS, $1.00 \mathrm{PP}$ ) depicts the tetraploid $P$. aquatica and $P$. lindigii (chromosome number unknown) as sister to a polytomy $(100 \%$ BS, 1.00 PP) of three subclades that includes diploid and tetraploid species: (1) two accessions of $P$. paradoxa, four accessions of $P$. minor, and the accession of $P$. maderensis (Menezes) Menezes (97\% BS, $1.00 \mathrm{PP})$; (2) two accessions of $P$. paradoxa plus the single accession of $P$. appendiculata Schult. $(86 \% \mathrm{BS}$, 1.00 PP); and (3) two P. coerulescens accessions (90\% BS, 1.00 PP). Members of lineage 3 possess floret types 4 ( $P$. lindigii), 5 and 6 (Figs. 2-3). The number of accessions for $P$. minor and $P$. paradoxa was increased to examine initial results pointing to the emergence of different accessions of these species in more than one clade.

trnT-F dataset. - The trnT-F region varied in length from 1669 ( $P$. californica) to 1650 ( $P$. paradoxa) nucleotides. Twenty-two gaps of 1 to 27 nucleotides were required in the alignment. The exclusion of the $3^{\prime}$ and $5^{\prime}$ ends of the alignment due to missing sequences and the removal of the poly $\mathrm{A}$ and $\mathrm{C}$ regions reduced the dataset to 1733 characters including indels. Of these characters, only $169(10 \%)$ were variable and 80 were parsimony-informative. The MP analyses generated 1120 equally parsimonious trees of 202 steps and CI and RI scores of 0.881 and 0.907 , respectively. Posterior probability support increased for all clades when compared to the MP bootstrap values. The topology of the BI tree is identical to the trnT-F MP consensus tree topology, but with higher resolution. Consequently, the BI tree is presented with both PP and BS values; nodes that collapsed during the MP analysis are noted on the tree (Fig. 4).

As in the ITS analysis, the monophyly of Phalaris is supported by maximum PP and 94\% BS (Fig. 4). Phalaris californica and $P$. peruviana emerge as consecutive sisters to the remaining species in the BI tree but support for this topology is not significant (Fig. 4). These nodes collapsed in the MP strict consensus tree, revealing a basal polytomy 
with the major clades (Fig. 4). The $x=6$ species appear sister to lineage 1 of the $x=7$ species, but with weak support for this relationship $(63 \% \mathrm{BS}, 0.87 \mathrm{PP})$. However, the internal structure of the $x=6$ clade is identical to that obtained in the ITS tree, but with lower BS and PP support. In lineage 1 (93\% MP, 1.00 PP), P. caroliniana is sister to a polytomy of P. angusta, P. lemmonii + P. platensis, and P. amethystina. Lineage 2 is recovered with low support and includes $P$. lindigii, a member of lineage 3 of the ITS phylogenetic tree. Lineage 3 is not recovered as such with the $\operatorname{trn} T-F$ data. The tetraploids $P$. aquatica, $P$. minor and $P$. maderensis emerge in a strongly supported group (98\% BS, $1.00 \mathrm{PP}$ ); unlike the ITS topology, they appear sister to lineage 2, but without significant support $(<50 \% \mathrm{BS}, 0.83 \mathrm{PP})$. Among remaining members of lineage 3 , the diploids $P$. coerulescens and $P$. paradoxa form a clade with maximum BS and PP support. One accession of $P$. paradoxa and $P$. appendiculata form a group with $96 \%$ BS and 1.00 PP support.

Combined ITS and trnT-F dataset. - The combined ITS/ trnT-F analyses resulted in four most parsimonious trees of 457 steps. The CI and RI values were 0.799 and 0.901 , respectively. The tree derived from the combined dataset is similar in overall topology to the one based on the ITS data, but with higher resolution (Fig. 5). Differences include the sister relationship of lineage 2 to lineage 3 rather than lineage 1 as seen in the ITS tree (Fig 3); neither relationship receive convincing support. There is higher resolution in members of lineage 1, with $P$. californica being sister to remaining members. The $P$. minor/P. maderensis clade gained strong support as sister to the $P$. paradoxa/P. coerulescens group.

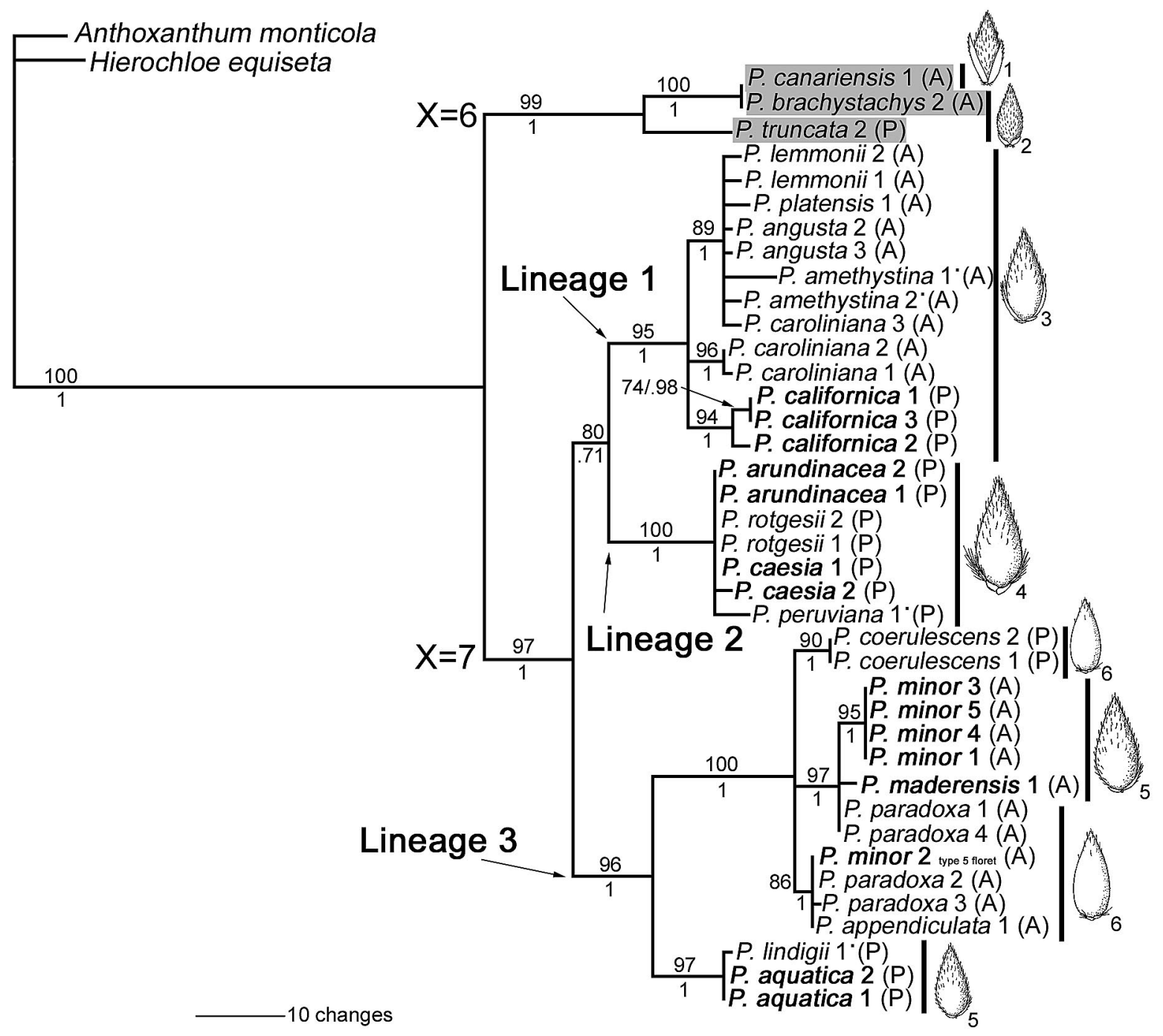

Fig. 3. ITS phylogram based on Bayesian inference. Parsimony bootstrap values are noted above branches and Bayesian posterior probabilities are below. Shaded section of the tree highlights species with $x=6$, and names shown in bold denote polyploid species. Floret types follow Fig. 2 . -= unknown chromosome number. $\mathrm{A}=$ annual and $\mathrm{P}=$ perennial habit. 


\section{DISCUSSION}

ITS vs. trnT-F signal. - The trnT-F alignment is approximately three times larger than the ITS alignment. However, the number of PI characters in the trnT-F is only 80 compared with 142 in the ITS. This difference in amount of informative characters could account for the lower resolution and support in the trnT-F based trees. Despite differences in phylogenetic signals, the CI and RI scores obtained from the analyses of the two regions are quite comparable and reflect a relatively low degree of homoplasy. The differential evolution of these two regions in different plant groups has been documented in several studies (Taberlet \& al., 1991; Baldwin, 1993; Alvarez \& Wendel, 2003; Neves \& al., 2005). Regardless of low phylogenetic signal in the $\operatorname{trn} T-F$ and lower resolution of the tree, the region provided useful information on species relationships and potential patterns of hybridization and polyploid evolution in Phalaris.

Phylogenetic relationships. - MP and BI analyses of ITS and $t r n T-F$ partitioned and combined data clearly demonstrate the single origin of the $x=6$ species within this monophyletic genus (Figs. 3-5). Further, both ITS and combined analyses recovered this lineage as sister to the remaining species of Phalaris (Figs. 3, 5). Morphologically, the $x=6$ species differ from the $x=7$ in having either type 1 (chaff-like sterile lemma) or type 2 florets (reduced coriaceous sterile lemma; Fig. 2). However, the annuals $P$. canariensis and $P$. brachystachys Link, although not sharing the same floret type, consistently appear in a strongly supported clade separate from the perennial P. truncata Guss ex Bertol. These morphological features add further support for the distinction of these $x=6$ species from the rest of Phalaris.

Similarly, the monophyly of the $x=7$ Phalaris species is also strongly supported (95\%, 1.00 PP ITS and 89\%, 1.00 PP combined). Although the trnT-F data did not recover this group as a monophyletic unit, most of its lineages correspond to those resolved in the ITS phylogeny (Figs. 3-4). The lower resolution in the $\operatorname{trn} T-F$ tree in the BI analysis (Fig. 4) is probably a reflection of the low phylogenetic signal in this genomic region. Support for the backbone of the tree in general is weak in the trnT-F tree compared with trees based on the ITS or combined data (Figs. 3-5). Therefore, the conflict between the $\operatorname{trn} T-F$

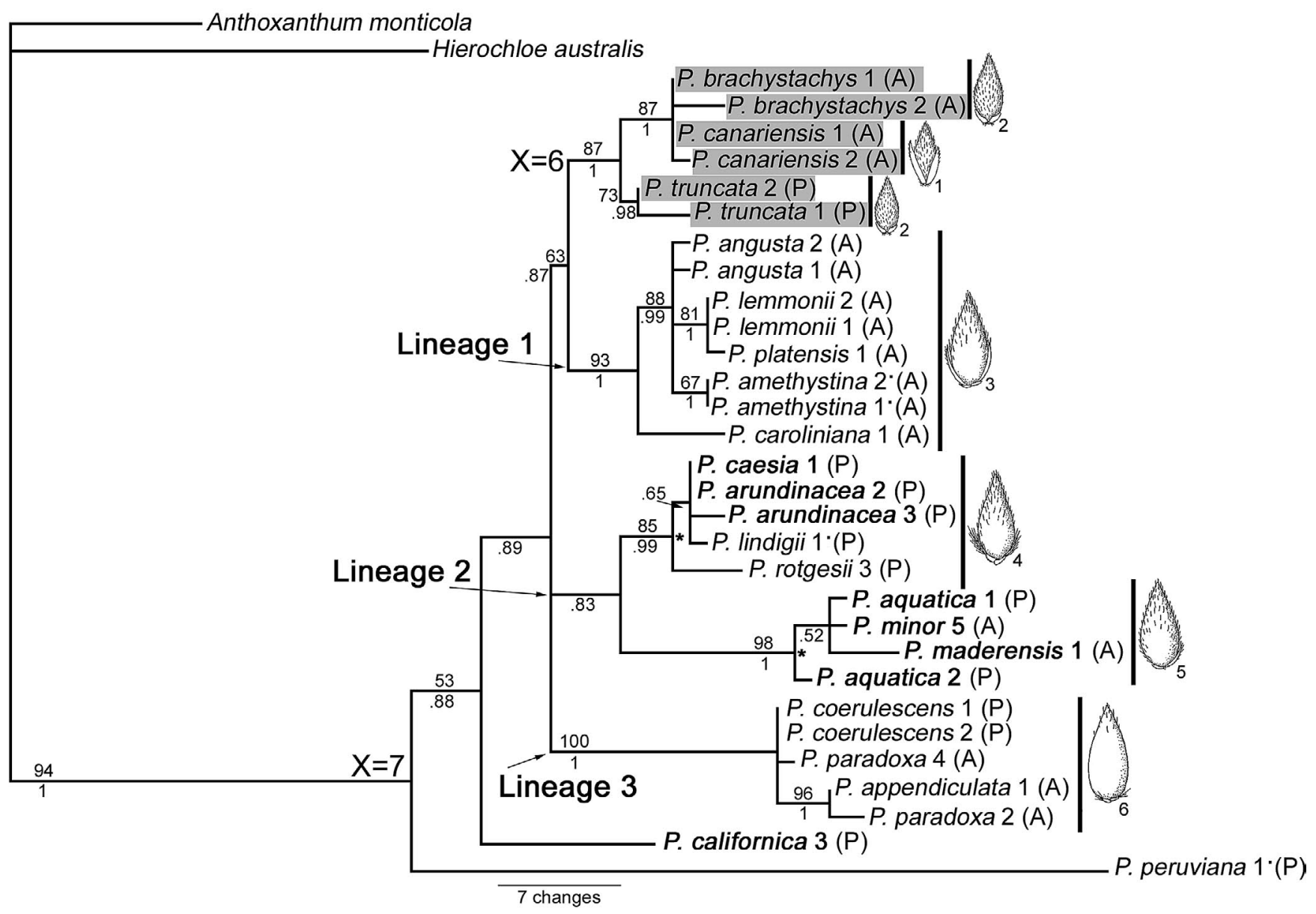

Fig. 4. trnT-F phylogram generated from Bayesian inference. Parsimony bootstrap results are above branches and Bayesian posterior probabilities are below. Shaded section of the tree highlights species with $x=6$, and names shown in bold denote polyploid species. ${ }^{*}=$ clade collapsed in the strict consensus maximum parsimony tree. $\bullet=$ unknown chromosome number. Floret types follow Fig. $2 . \mathrm{A}=$ annual and $\mathrm{P}=$ perennial habit. 
and ITS tree topologies represents a case of soft incongruence (Seelanan \& al., 1997), and consequently, expanding the plastid dataset might clarify this situation. The emergence in the $\operatorname{trnT} T-F$ tree of $P$. californica and $P$. peruviana as sister to remaining Phalaris may be due to long-branch attraction (Felsenstein, 1978), particularly for the latter species (Fig. 4). However, both $P$. peruviana and $P$. californica share with the outgroup species unique SNP mutations and six indels in the trnT- $F$ alignment. These shared characters might imply historic intergeneric hybridization events and subsequent lineage sorting (Doyle, 1992; Wendel \& Doyle, 1998), and could have contributed to the conflicting placement of $P$. californica and $P$. peruviana.

As noted earlier, three major lineages are evident for the $x=7$ species. Lineage 1 (Figs. 3-5) represents all North American and most South American species, and includes four diploids (P. angusta, $P$. lemmonii, $P$. platensis, $P$. caroliniana), one tetraploid (P. californica), and one species with unknown chromosome number $(P$. amethystina). Members of this lineage share floret type 3 (Figs. 2, 5). All species are annuals except for the tetraploid $P$. californica, which is a perennial. The emergence of $P$. californica as sister to remaining species may imply that perennial habit and tetraploidy are ancestral states. However, the inconsistent placement of $P$. californica in the partitioned and combined analyses renders such a conclusion difficult to support at this point. Additional molecular markers are needed to illustrate the mode of habit and polyploid evolution in this lineage.

Lineage 2, as defined in the ITS and combined analyses, encompasses the broadly distributed $P$. arundinacea (tetraploid), along with the European Mediterranean $P$. caesia (hexaploid) and $P$. rotgesii (diploid), and South American $P$. peruviana (chromosome number unknown). The monophyly

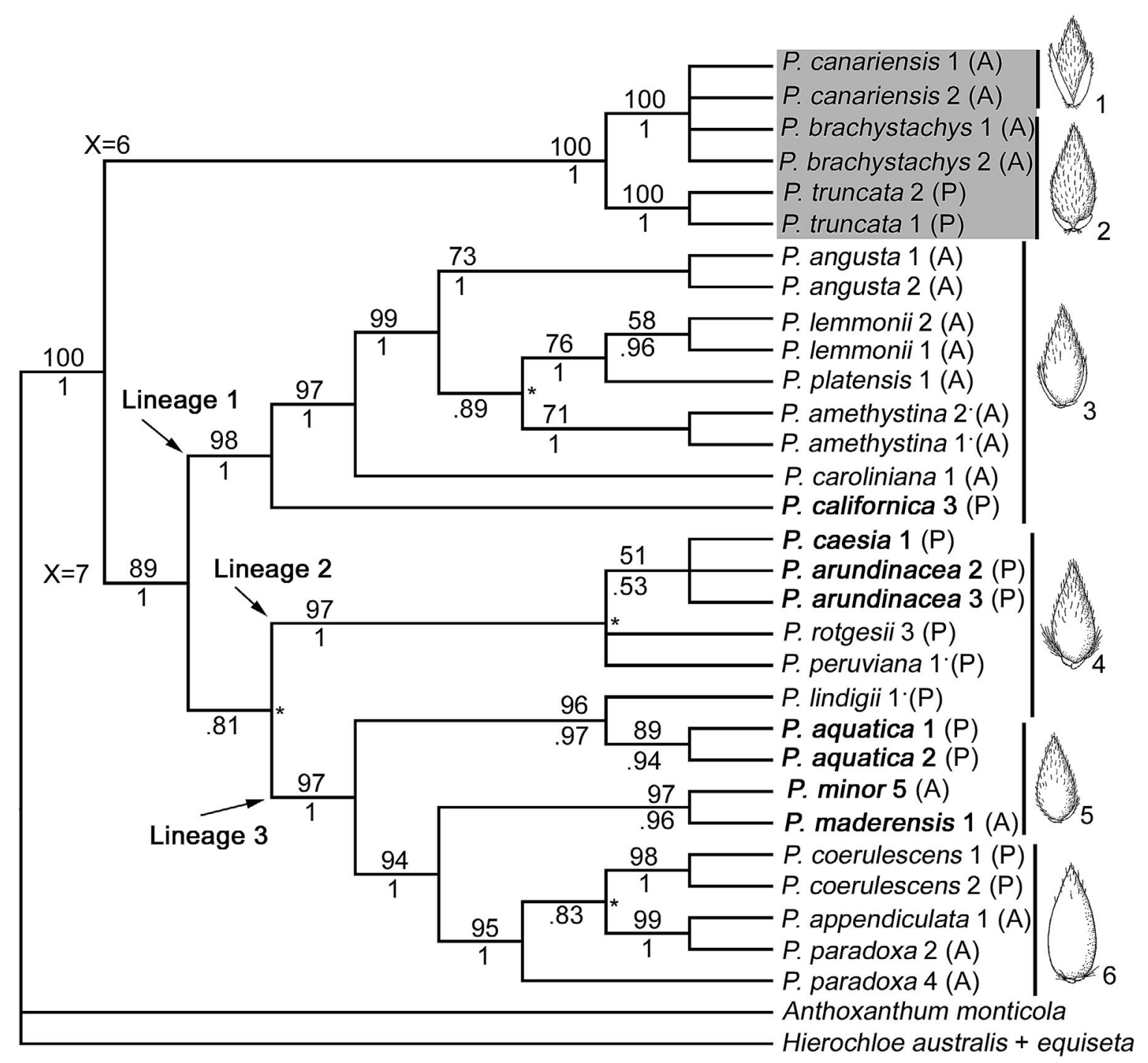

Fig. 5. Combined ITS and trnT-F phylogeny based on maximum parsimony and Bayesian inference. Shaded section of the tree highlights species with $x=6$, and names shown in bold denote polyploid species. $*=$ nodes collapsed in the strict consensus maximum parsimony tree. $\bullet=$ unknown chromosome number. Floret types follow the structure defined in Fig. 2 . A= annual and $\mathrm{P}=$ perennial habit. 
of these four species receives strong BS and maximum PP support in all analyses except for the $85 \%$ BS support in the trnT-F based tree (Figs. 3-5). The four species also share the unique morphological features of floret type 4 (Fig. 2). This clade stands out as an excellent example of evolution through polyploidy and its association with geographic expansion. The diploid $P$. rotgesii is found in small, scattered populations confined to Corsica Island (Europe). The only tetraploid in its clade, $P$. arundinacea, is a robust species distributed in most temperate habitats in the Northern Hemisphere (Fig. 1). The hexaploid $P$. caesia is distributed in southern France, northern Spain, Portugal, the Middle East, and northern, eastern, and southern Africa (Baldini, 1995). Thus, we propose that the addition of a third genome copy has not resulted in increased geographic expansion but in the occupation of certain habitats such as the afroalpine grasslands and European lacustrine areas (Baldini, 1995).

The trnT-F phylogeny suggests that the morphologically variable diploid $P$. rotgesii is a potential progenitor of both polyploid species. The chromosome number and evolutionary origin of $P$. peruviana is currently unknown. This Neotropical species differs from other members of its clade by the narrow ovoid panicle, acuminate and keeled glumes and pubescent sterile lemmas (Baldini, 1995). The phylogenetic relationship of this South American species to other species in its clade remains ambiguous due to the polytomy. The presence of only one diploid species in this lineage and the existence of unique morphological synapomorphies within this diploid/tetraploid/ hexaploid complex imply that autopolyplodization may have played a role in its evolution. Soltis \& al. $(2007,2010)$ indicated that there are more autopolyploids than have been recognized. However, a conclusive assessment awaits a chromosome count for P. peruviana.

Lineage 3 of the $x=7$ clade is strongly supported in the ITS and combined data analyses ( $96 \%$ and $97 \%$ BS, $1.00 \mathrm{PP}$ ). It consists of species endemic to temperate Europe, some of which are introduced to North America, and one species, P. lindigii, exists in South America. Members of this group exhibit diploid-tetraploid relationships (P. lindigii lacks a chromosome count). The phylogenetic relationships resolved in this clade depict an intriguing pattern of polyploid evolution. The tetraploid $P$. aquatica and the South American P. lindigii are strongly supported as sister to remaining species of this lineage, which includes both diploids and tetraploids (Figs. 3, 5). A conclusion on polyploid evolution within this lineage requires chromosome counts for $P$. lindigii, which is known only from a few collections. Phalaris lindigii displays intermediate features between $P$. aquatica and $P$. arundinacea, such as a cylindrical panicle and keeled glumes as in P. aquatica and two equal sterile lemmas and a truncate ligule as in $P$. arundinacea. In the trnT-F based tree, $P$. lindigii grouped with $P$. arundinacea in lineage 2 (Fig. 4). This may imply that $P$. lindigii is a hybrid between $P$. arundinacea (maternal) and P. aquatica (paternal). Natural and artificial hybrids between these two species have been reported, and in the case of the artificial hybrids success was higher with $P$. arundinacea as the maternal parent (Jenkin $\&$ Sethi, 1932).
The remaining tetraploids in lineage 3 ( $P$. minor, P. maderensis) form a strongly supported clade based on trnT-F data, and appear in a clade with one accession of diploid P. paradoxa based on the ITS information (Figs. 3, 5). The latter relationship, which received near maximum BS and PP support, points to the potential paternal genome donation of the diploid $P$. paradoxa to the two tetraploids. The appearance of one of the accessions of $P$. minor with other accessions of $P$. paradoxa in different clades of the ITS tree may imply multiple origins for the tetraploid $P$. minor. We observed several haplotypes in both ITS and trnT-F for diploid P. paradoxa, which lends support to the potential multiple origin of tetraploid $P$. minor. Phalaris paradoxa and P. minor overlap in geographic distribution (Baldini, 1995), increasing the likelihood of derivation of one of the genomes of the tetraploid P. minor from the former species. All the tetraploids in this lineage possess floret type 5 (floret with one developed lemma) as a synapomorphy, while the diploids share floret type 6 (sterile lemmas nearly obsolete; Fig. 2). Phalaris paradoxa is a highly variable species (Anderson, 1961) with three recognizable subtypes of sterile spikelets (glumes clavate, reduced and normal). Phalaris appendiculata is considered one of the morphological extremes of $P$. paradoxa (Baldini, 1995). We therefore treat $P$. appendiculata as a morphotype of $P$. paradoxa without any taxonomic rank.

The tetraploid $P$. maderensis is a rare species found on the island of Madeira off the western coast of Africa near Morocco. Baldini (1995) proposed that $P$. maderensis is derived from $P$. minor since the two share similar floret morphologies. This study suggests a close relationship between the two; however, only one accession of $P$. maderensis was available due to its rarity. Lineage 3 deserves detailed study with denser sampling at the population level, additional sequences and chromosome banding to determine the pattern of species and polyploid evolution in this complex clade.

Floret evolution in Phalaris. - Phalaris stands out as the most specialized genus in the subtribe Phalaridinae sensu Clayton \& Renvoize (1986). All three genera of the tribe possess one central fertile floret and two lower fertile or sterile ones (sterile lemmas). In Hierochloe, the lower florets are either male or sterile but are as large as the central fertile floret, compared with Anthoxanthum where the lower florets are empty, rarely one or both are male, though are as large as those found in Hierochloe. Lower florets in Phalaris have undergone extreme reduction in size and are always sterile. Within Phalaris, the six floret types (Fig. 2) follow a successive trend of reduction when mapped on the phylogenetic trees (Figs. 3, 5). This trend of reduction starts from the $x=6$ clade where the sterile lemmas tend to be relatively broad (types 1 and 2) to the obsolete sterile lower lemmas (type 6 floret) found in P. paradoxa and P. coerulescens. Therefore, transitional reduction in floret structure is evident from Hierochloe to Anthoxanthum and continued with Phalaris, where it reaches an extreme state deeper in the evolution of the latter genus.

Patterns associated with polyploidy. - Polyploidy is quite prevalent in Poaceae, with about $80 \%$ of the species considered to be of polyploid origin (Stebbins, 1985; Hunziker \& Stebbins, 1987; Levy \& Feldman, 2002; Hilu, 2006). 
Polyploidy has also been considered as an important factor in the diversification of the family (Levy \& Feldman, 2002). Hilu (2006) demonstrated a correlation between polyploidy, perennial habit and increase in species number in grass genera. The perennial habit provides a time buffer for newly formed polyploids to regain fertility. Polyploid evolution and species diversification in Phalaris occurred only in association with the $x=7$ basic chromosome number. The $x=6$ species, although possessing both annual (P. canariensis, P. brachystachys) and perennial ( $P$. truncata) habits, remained diploid. This is particularly striking in the case of $P$. truncata where self-incompatibility has been documented (Heslop-Harrison, 1982; Oram, 2004), a breeding system that promotes allopolyploid evolution.

The emergence of a basal split in Phalaris into two major clades each composed strictly of $x=6$ or $x=7$ species implies early evolution of aneuploidy. Although $x=7$ is a common number in the traditional Aveneae, aneuploid derivatives $(x=2,4$, $5,6,8$, and 9) from that number are not uncommon, with $x=6$ confined to Phalaris (Hilu, 2004). Variation in basic chromosome number within genera have been reported, such as $x=4$, 5, 7 and 9 in Milium L., and $x=5$ and 7 in Briza L. (Stebbins, 1982, 1985; Watson \& Dallwitz, 1982; De Wet, 1987; Hunziker \& Stebbins, 1987). Avdulov (1931), Ambastha (1956), and Kadir (1974) postulated that Phalaris species with $2 n=12$ might have been derived from those with $2 n=14$ by the fusion of two chromosomes, thus assuming $x=7$ as the ancestral state. Closest genera recovered in the same lineage (Schneider \& al., 2009), such as Briza, Anthoxanthum, Hierochloe, and Airopsis, possess basic chromosome numbers of 5,7 , and 4 , respectively (Clayton \& Renvoize, 1986; Hilu, 2004). Therefore, either $x=6$ evolved de novo in Phalaris, or alternatively a common ancestor to the genus with $x=6$ is extinct.

The association between geographic distribution, ecological adaptation and basic chromosome number in the genus is striking. Members of this $x=6$ clade are confined to Mediterranean Europe in terms of natural distribution. The expansion of the annuals $P$. canariensis and $P$. brachystachys to North America was the result of relatively recent human introduction (Barkworth, 2007). In contrast, the perennial P. truncata is a rare species with fragmented distribution in Mediterranean Europe (Baldini, 1993). Therefore, low species diversification, lack of polyploidy, and restricted geographic distribution could imply that the $x=6$ group is an evolutionary dead-end lineage. On the other hand, in the case of $x=7$ clade, species diversification, polyploidy evolution (possibly both auto- and allopolyploidy), and expansion to other continents and new habitats are evident (Fig. 1). The tetraploid $P$. arundinacea has the widest modern distribution, particularly in eastern parts of Asia where other Phalaris species are not found. The $x=7$ lineage also shows the evolution of new diploids ( $P$. lemmonii, $P$. caroliniana, $P$. platensis, $P$. angusta) and tetraploids (P. californica) in North and South America. Geographically, $P$. paradoxa and $P$. minor overlap in distribution and show a strong presence in California along with $P$. aquatica. Remaining diploid and tetraploid species with $x=7$ exhibit wide geographic distribution, although in some cases, such as the hexaploid $P$. caesia, the distribution is disjunct. Regardless, an ecological advantage appears to have been conferred with polyploidy superimposed on a basic chromosome number of $x=7$. These hypotheses can be tested in an eco-physiological study. With the apparent early split in the genus into the $x=6$ and $x=7$ lineages and the confinement of the former lineage to the Mediterranean region, it appears that Mediterranean Europe is likely to be the center of origin for the genus, rendering western North America, as a secondary center of diversity and polyploidy. However, a biogeographic study is underway to evaluate this hypothesis.

Phalaris therefore presents a potentially valuable case study in speciation, chromosomal evolution, and biogeography in the grass family due to its global distribution, notable variation in morphologies, and the key role of polyploidy in its evolution.

\section{ACKNOWLEDGEMENTS}

We thank Rachel Moebus and Jenni Witten (Virginia Tech) for their devoted efforts in laboratory work, the curators of the herbaria B, BR, CONC, CSCH, FI, GH, HSC, OBI, RSA, SGO, US, VPI, and WU, Elia Menicagli (University of Florence) for technical support with graphics, and Anne Maury (Florence) for providing the floret illustration. This work was supported in part by grants from the Virginia Academy of Science (to RK) and The University of Florence (to RMB).

\section{口 LITERATURE CITED}

Alvarez, I. \& Wendel, J.F. 2003. Ribosomal ITS sequences and plant phylogenetic inference. Molec. Phylog. Evol. 29: 417-434.

Ambastha, H.N.S. 1956. Cytological investigations in Phalaris. Genetica 28: 64-98.

Anderson, D.H. 1961. Taxonomy and distribution of the genus Phalaris. Iowa State J. Sci. 36: 1-96.

Avdulov, N.P. 1931. Kario-sistematicheskoe issledovanie semejstva zlakov. Trudy po Prikladnoj Botanik, Genetike u Selektsii Prilož. 44: 1-428. = Karyo-systematische Untersuchung der Familien Gramineen. Bull. Appl. Bot., Genet. Pl. Breed. Suppl. 44: 1-428. [in Russian and German]

Baldini, R.M. 1993. The genus Phalaris L. (Gramineae) in Italy. Webbia 47: 1-53.

Baldini, R.M. 1995. Revision of the genus Phalaris L. (Gramineae). Webbia 49: 265-329.

Baldini, R.M. \& Jarvis, C.E. 1991. Typification of some Linnaean names in Phalaris (Gramineae). Taxon 40: 475-485.

Baldwin, B.G. 1993. Molecular phylogenetics of Calycadenia (Compositae) based on ITS sequences of nuclear ribosomal DNA: Chromosomal and morphological evolution reexamined. Amer. J. Bot. 80: 222-238.

Barker, F.K. \& Lutzoni, F.M. 2002. The utility of the incongruence length difference test. Syst. Biol. 51: 625-637.

Barkworth, M.E. 2007. Phalaris L. Pp. 764-773 in: Barkworth, M.E., Capels, K.M., Long, S., Anderton, L.K. \& Piep, M.B. (eds.), Flora of North America north of Mexico. New York, Oxford: Oxford University Press.

Casler, M.D., Phillips, M. \& Krohn, A.L. 2009. DNA polymorphisms reveal geographic races of reed canarygrass. Crop Sci. 49: 2139-2148.

Clayton, W.D. \& Renvoize S.A. 1986. Genera Graminum: Grasses of the World. London: HMSO. 
Cunningham, C.W. 1997. Can three incongruence tests predict when data should be combined? Molec. Biol. Evol. 14: 733-740.

Darlu, P. \& Lecointre, G. 2002. When does the incongruence length difference test fail? Molec. Biol. Evol. 19: 432-437.

De Wet, J.M.J. 1987. Hybridization and polyploidy in the Poaceae. Pp. 188-194 in: Soderstrom, T.R., Hilu, K.W., Campbell, C.S. \& Barkworth, M.A. (eds.), Grass systematics and evolution. Washington D.C.: Smithsonian Institution Press.

Dolphin, K., Belshaw, R., Orme, C.D.L. \& Quicke, D.L.J. 2000. Noise and incongruence: Interpreting results of the incongruence length difference test. Molec. Phylog. Evol. 17: 401-406.

Döring, E., Albrecht, J., Hilu, K. W. \& Röser, M. 2007. Phylogenetic relationships in the Aveneae/Poaceae complex (Pooideae, Poaceae). Kew Bull. 62: 407-424.

Downie, S.R. \&. Katz-Downie, D.S. 1996. A molecular phylogeny of Apiaceae subfamily Apioideae: Evidence from nuclear ribosomal DNA Internal Transcribed Spacer sequences. Amer. J. Bot. 83: 234-251.

Doyle, J.J. 1992. Gene trees and species trees: Molecular systematics as one-character taxonomy. Syst. Bot. 17: 144-163.

Doyle, J.J. \& Doyle, J.L. 1990. Isolation of plant DNA from fresh tissue. Focus 12: 13-25.

Farris, J.S., Källersjö, M., Kluge, A.G. \& Bult, C. 1995. Constructing a significance test for incongruence. Syst. Biol. 44: 570572.

Felsenstein, J. 1978. Cases in which parsimony or compatibility methods will be positively misleading. Syst. Zool. 27: 401-410.

Felsenstein, J. 1985. Confidence limits on phylogenies: An approach using the bootstrap. Evolution 39: 783-791.

Gillespie, L.J., Soreng, R.J., Bull, R.D., Jacobs, S.W.L. \& RefulioRodriguez, N.F. 2008. Phylogenetic relationships in subtribe Poinae (Poaceae, Poeae) based on nuclear ITS and plastid trnTtrnLtrnF sequences. Botany 86: 938-967.

Henrard, J.T. 1938. Vicarious grasses, as demonstrated by a new species of Phalaris from South America. Blumea 3: 168-172.

Heslop-Harrison, J. 1982. Pollen-stigma interaction and cross-incompatibility in the grasses. Science 215: 1358-1364.

Hilu, K.W. 2004. Phylogenetics and chromosomal evolution in the Poaceae (grasses). Austral. J. Bot. 52: 13-22.

Hilu, K.W. 2006. Skewed distribution of species number in grass genera: Is it a taxonomic artifact? Pp. 165-176 in: Hodkinson, T. \& Parnell J.A.N. (eds.), Reconstructing the tree of life: Taxonomy and systematics of species rich taxa. Boca Raton: CRC Press.

Hsiao, C., Chatterton, N.J., Asay, K.H. \& Jensen, K.B. 1995. Molecular phylogeny of the Pooideae (Poaceae) based on nuclear rDNA (ITS) sequences. Theor. Appl. Genet. 90: 389-398.

Huelsenbeck, J.P. \& Ronquist, F. 2001. MrBayes: Bayesian inference of phylogenetic trees. Bioinformatics 17: 754-755.

Hunziker, J.H. \& Stebbins, G.L. 1987. Chromosomal evolution in the Gramineae. Pp. 179-187 in: Soderstrom, T.R., Hilu, K.W., Campbell, C.S. \& Barkworth, M.A. (eds.), Grass systematics and evolution. Washington, D.C.: Smithsonian Institution Press.

Jenkin, T.J. \& Sethi, B.L. 1932. Phalaris arundinacea, Ph. tuberosa, their $F_{1}$ hybrids and hybrid derivatives. J. Genet. 26: 1-38.

Kadir, Z.B.A. 1974. DNA values in the genus Phalaris (Gramineae). Chromosoma 45: 379-386.

Kim, E.S., Bolsheva, N.L., Samatadze, T.E., Nosov, N.N., Nosova, I.V., Zelenin, A.V., Punina, E.O., Muravenko, O.V. \& Rodionov, A.V. 2009. The unique genome of two-chromosome grasses Zingeria and Colpodium, its origin, and evolution. Russ. J. Genet. 45: 1329-1337.

Kodela, P.G., Weiller, C.M. \& Thompson, I.R. 2009. Phalaris. Pp. 145-152 in: Wilson, A. (ed.), Flora of Australia, vol. 44A, Poaceae, 2. Canberra: ABRS/CSIRO.

Larget, B. \& Simon, D. 1999. Markov Chain Monte Carlo algorithms for Bayesian analysis of phylogenetic trees. Molec. Biol. Evol. 16: $750-759$.
Levy, A.A. \& Feldman, M. 2002. The impact of polyploidy on grass genome evolution. Pl. Physiol. 130: 1587-1593.

Lewis, P.O. 2001. Phylogenetic systematics turns over a new leaf. Trends Ecol. Evol. 16: 30-37.

McWilliam, J. \& Neal-Smith, C. 1962. Tetraploid and hexaploid chromosome races of Phalaris arundinacea L. Austral. J. Agric. Res. 13: $1-9$.

Merigliano, M.F. \& Lesica, P. 1998. The native status of reed canarygrass (Phalaris arundinacea L.) in the Inland Northwest, USA. Nat. Areas J. 18: 223-230.

Müller, K. 2004. Quickalign, version 1.03. http://bioinfweb.info/Soft ware/QuickAlign.

Müller, K. 2005. SeqState-primer design and sequence statistics for phylogenetic DNA data sets. Appl. Bioinformatics 4: 65-69.

Neves, S.S., Swire-Clark, G., Hilu, K.W. \& Baird, W.V. 2005. Phylogeny of Eleusine (Poaceae: Chloridoideae) based on nuclear ITS and plastid trnT-trnF sequences. Molec. Phylog. Evol. 35: 395-419.

Oram, R.N. 2004. Phalaris canariensis is a domesticated form of P. brachystachys. Genet. Resources Crop Evol. 51: 259-267.

Oram, R.N., Ferreira, V., Culvenor, R.A., Hopkins, A.A. \& Stewart, A. 2009. The first century of Phalaris aquatica L. cultivation and genetic improvement: A review. Crop Pasture Sci. 60: 1-15.

Parthasarathy, N. 1938. Cytogenetical studies in Oryzeae and Phalarideae. J. Genet. 37: 1-40.

Paunero, R.E. 1948. Revisión de las especies españolas del género Phalaris. Anales Jard. Bot. Madrid 8: 475-522.

Posada, D. \& Crandall, K.A. 1998. ModelTest: Testing the model of DNA substitution. Bioinformatics 14: 817-818.

Quintanar, A., Castroviejo, S. \& Catalan, P. 2007. Phylogeny of the tribe Aveneae (Pooideae, Poaceae) inferred from plastid trnT-F and nuclear ITS sequences. Amer. J. Bot. 94: 1554-1569.

Rauschert, S. 1969. Zur Nomenklatur der Farn- und Blütenpflanzen Deutschlands (II). Feddes Repert. 79: 409-421.

Ronquist, F. \& Huelsenbeck J.P. 2003. MrBayes 3: Bayesian phylogenetic inference under mixed models. Bioinformatics 19: 1572-1574.

Schneider, J., Döring, E., Hilu, K.W. \& Röser, M. 2009. Phylogenetic structure of the grass subfamily Pooideae based on comparison of plastid matK gene-3'trnK exon and nuclear ITS sequences. Taxon 58: 405-424.

Seelanan, T., Schnalbel, A. \& Wendel, J.F. 1997. Congruence and consensus in the cotton tribe. Syst. Bot. 22: 259-290.

Simmons, M.P. \& Ochoterena, H. 2000. Gaps as characters in sequence-based phylogenetic analyses. Syst. Bot. 49: 369-381.

Soltis D.E., Buggs, R.J.A., Doyle, J.J. \& Soltis, P.S. 2010. What we still don't know about polyploidy. Taxon 59: 1387-1403.

Soltis, D.E., Soltis, P.S., Schemske, D.W., Hancock, J.F., Thompson, J.N., Husband, B.C. \& Judd, W.S. 2007. Autopolyploidy in angiosperms: Have we grossly underestimated the number of species? Taxon 56: 13-30.

Soreng, R.J. \& Davis, J.I. 2000. Phylogenetic structure in Poaceae subfamily Pooideae as inferred from molecular and morphological characters: Misclassification versus reticulation. Pp. 61-74 in: Jacobs, S.W.L. \& Everett J. (eds.), Grasses: Systematics and evolution. Collingwood: CSIRO.

Soreng, R.J., Peterson, P.M., Davidse, G., Judziewicz, E.J., Zuloaga, F.O., Filgueiras, T.S. \& Morrone, O. (eds.). 2003. Catalogue of New World grasses (Poaceae) IV: Subfamily Pooideae. Washington, D.C.: National Museum of Natural History.

Stebbins, G.L. 1971. Chromosomal evolution in higher plants. London: Arnold.

Stebbins, G.L. 1982. Major trends of evolution in the Poaceae and their possible significance. Pp. 3-36. in: Estes, J.R., Tyrl, R.J. \& Brunken, J.N. (eds.), Grasses and grasslands: Systematics and ecology. Norman: University of Oklahoma Press.

Stebbins, G.L. 1985. Polyploidy, hybridization, and the invasion of new habitats. Ann. Missouri Bot. Gard. 72: 824-832. 
Swofford, D.L. 2002. PAUP*: Phylogenetic analysis using parsimony (*and other methods), version 4.0b10. Sunderland, Massachusetts: Sinauer.

Taberlet, P., Gielly, L., Pautou, G. \& Bouvet, J. 1991. Universal primers for amplification of three non-coding regions of chloroplast DNA. Pl. Molec. Biol. 17: 1105-1109.

Valdés, B. \& Scholz, H. 2006. The Euro+Med treatment of Gramineae - a generic synopsis and some new names. Willdenowia 36: $657-669$.
Watson, L. \& Dallwitz, M.J. 1982. Grass genera: Descriptions, 4th ed. Canberra: Australian National University.

Wendel, J.F. \& Doyle, J.J. 1998. Phylogenetic incongruence: Windows into genome history and molecular evolution. Pp. 265-296 in: Soltis, D.E., Soltis, P.S. \& Doyle, J.J. (eds.), Molecular systematics of plants II: DNA sequencing. Norwell: Kluwer Academic Publishers.

Woods, K., Hilu, K.W., Borsch, T. \& Wiersema, J.H. 2005. Patterns of variation and systematics of Nymphaeae odorata II. Sequence information from ITS and trnL-trnF. Syst. Bot. 30: 481-493.

Appendix. Phalaris species used, geographic origin of the material, information on the herbarium vouchers, and GenBank numbers are noted. The number appended to each species name is used throughout this study to identify the multiple accessions of the species. $2 n=$ somatic chromosome number. Numbers following USDA refer to collection numbers for the accessions in germplasm resources information network (GRIN).

Species, chromosome number, origin, voucher, GenBank accession (ITS, $\operatorname{trn} T-F)$

Phalaris amethystina Trin., 2n=14: 1, Chile, Bio-Bio, V. Finot \& R. Solis 2247 (CONC-CH), JF951053, JF951091; 2, South America, s.coll. 108407 (SGO), JF951060, JF951092. P. angusta Nees ex Trin., 2n=14: 1, U.S.A., Louisiana, R.D. Thomas 87875 (VPI), JF951112, -; 2, Brazil, USDA 310292, JF951054, JF951093; 3, Brazil, Rio Grande do Sul, W. Barreto 14 (US), JF951055, -. P . appendiculata Schult., 2n=14: 1, Ethiopia, USDA 331404 , JF951071, JF951107. $\boldsymbol{P}$. aquatica L., $2 n=28$ : 1, U.S.A., California, S. Boyd 11476 (RSA), JF951076, JF951113; 2, Netherlands, USDA 284200, JF951056, JF951094. P. arundinacea L., $2 n=28:$ 1, U.S.A., Virginia, D.W. Ogle 97462 (VPI), JF951077, -; 2, Canada, USDA 387928, JF951075, JF951095; 3, Kazakhstan, USDA 435303, -, JF951096. P. brachystachys Link, 2n=12: 1, U.S.A., California, Lowell Ahart 10286 (CSCH), -, JF951114; 2, Algeria, USDA 239820 , JF951057, JF951097. P. caesia Nees, 2n=42: 1, France, Montpellier, M. Kerguelen 8983 (FI), JF951061, JF951115; 2, Ethiopia, E. DeWilde 6804 (BR), JF951062, -. P. californica Hook. \& Arn., $2 n=28$ : 1, U.S.A., California, D. Keil s.n. (OBI), JF951063, -; 2, U.S.A., California, J.D. Prouty 857 (CSCH), JF951078, -; 3 , U.S.A., California, S.H. Bicknell s.n. (HSC), JF951064, JF951098. P. canariensis L., 2n=12: 1, Egypt, USDA 251274, JF951058, JF951100; 2, Brazil, USDA 163357, -, JF951099. P. caroliniana Walt., $2 n=14$ : 1, U.S.A., Georgia, R.K. Godfrey 68477 (VPI), JF951079, JF951101; 2, U.S.A., Lousiana, R.D. Thomas 133507 (VPI), JF951080, -; 3, U.S.A., Texas, T. Boulware 153320327 (US), JF951065, -. P. coerulescens Desf., 2n=14: 1, Italy, Sardinia, R.M. Baldini s.n. (FI), JF951081, JF951116; 2, United Kingdom, USDA 239340, JF951066, JF951102. P. lemmonii Vasey, $2 n=14$ : 1, U.S.A., California, D. Bramlet 2290 (RSA), JF951082, JF951117; 2 , U.S.A., California, D. Keil \& C.D Oyler 25383 (OBI), JF951067, JF951103. P. lindigii Baldini, $2 n=$ unknown: 1, Ecuador, Carchi, P. Peterson \& al. 3237425 (US), JF951068, JF951104. P. maderensis (Menezes) Menezes, 2n=28: 1, Portugal, Madeira Island, J.A. Carvalho s.n. (FI), JF951083, JF951118. P. minor Retz. $2 n=28$ : 1, Italy, Tuscany, R.M. Baldini s.n. (FI), JF951084, -; 2, Italy, Calabria, R.M. Baldini s.n. (FI), JF951085, -; 3, U.S.A., California, J. Gregory 857 (SD), JF951086, -; 4, Turkmenistan, Konovalovat 16726 (BR), JF907187, -; 5, South Africa, USDA 208404, JF951069, JF951105. P. paradoxa L., 2n=14: 1, Italy, Tuscany, Z.R.A. Da Silva s.n. (FI), JF951087, -; 2, U.S.A., California, J.R. Reeder 5665 (RSA), JF951088, JF951119; 3, Italy, Sardinia, R.M. Baldini s.n. (FI), JF951089, -; 4, Cyprus, USDA 239845, JF951070, JF951106. P. peruviana H. Scholz \& Gutte, 2n=unknown: 1 , Peru, P. Gutte \& G. Miller 8717 (B, Type specimen), JF951072, JF951108. P. platensis Henrard ex Wacht, 2n=14: 1, Australia, USDA 239339, JF951073, JF951109. P. rotgesii (Husnot) Baldini, $2 n=14$ : 1, France, Corsica, R.M. Baldini 12/8 (FI) JF951090, -; 2, France, Corsica, R.M. Baldini 15/1 (FI), JF951074, JF951110. P. truncata Guss. ex Bertol., $2 n=12$ : 1, Italy, Tuscany, R.M. Baldini 15/22 (FI), -, JF951120; 2, Tunisia, USDA 535561, JF951059, JF951111. Briza minor L., 2n=10: 1, Hsiao \& al. (1995), L36510. Hierochloe australis (Schrad.) Roem. \& Schult., 2n=14: 1, Quintinar \& al. (2007), DQ631447.1. Hierochloe equiseta Zotov, 2n=14: 1, Gardner \& al. (unpub.), AY705901.1. Anthoxanthum monticola (Bigelow) Veldkamp, 2n=10: 1, Gillespie \& al. (2008), DQ353953.1; 2, Kim \& al. (2009), EF577511.1. 